animal and plant worlds, ${ }^{12}$ and it is hardly surprising to find them present also in man. ${ }^{3}{ }^{4}$ The environment of most living things fluctuates regularly with changes of light and temperature which are diurnal, or seasonal, or annual, with a monthly cycle of moonlight as well. There are adaptive advantages to the organism in temporal harmony with its usual environment.

The human baby is not born with these daily rhythms. They develop slowly during the first twelve to twenty weeks of independent life, ${ }^{2}$ later in the premature infant, and at different times for the different rhythms in the same individual. These facts once again emphasize that the rhythms are essentially endogenous, and not a passive response to the rhythmic environment. Their physiological mechanisms remain largely obscure, but it seems likely that human rhythms are imposed by the central nervous system (hypothalamic clocks, perhaps), which releases hormones at different times and so evokes some of the cyclical phenomena we observe. Thus under hypothalamic orders there is a diurnal variation in the level of plasma eortisol, with a peak in the early morning, and evidence ${ }^{5}$ that these changes in level in turn control the urinary rhythm of potassium excretion. Adrenal corticoids also have some influence on the other urinary rhythms, since raised levels of corticosteroid in plasma and urine, whether from disease or drugs, are associated with suppression of the normal rhythms.

One difficulty in all research on rhythms is to disentangle the mechanism of time-keeping from the mechanism that shows us the time. The spring and balance wheel may be hypothalamic, so to speak, while the urinary sodium represents a hand of the clock. Hormones which influence renal function may make the kidney able or unable to respond in rhythm to a timed stimulus from elsewhere. They do not indicate what that stimulus is. More light on both kinds of mechanism will come from more clinical studies. Much remains to be done in observing changes in diurnal rhythms in infancy and in extreme age and in various endocrinological and neurological disorders. Encephalitis lethargica was noteworthy for its inverted sleep rhythm, and if it is coming back there will be invaluable opportunities for studying its changed rhythms by modern methods. Diurnal rhythms also require study after psychotropic drugs or neurosurgical treatment.

To the psychiatrist diurnal variation in patients' behaviour is often striking. The person who is very depressed in the mornings may appear quite cheerful in the afternoons-to such an extent that the time of an outpatient appointment may make all the difference to a clinical assessment. This is one of the many difficulties in judging the value of treatment for endogenous depression. Dr. A. Elithorn and his colleagues have seized on this condition to study urinary electrolyte excretion rhythms, and their report appears at page 1620 of the B.M.f. this week. A substantial number of normal people feel inactive in the mornings and better by evening, ${ }^{7}$ so that the mood swing in depressives might be an exaggeration of the normal, and if so it might be expected that the urinary electrolyte rhythm would show a similar sharpening in depressive illness. Dr. Elithorn and his colleagues find

1 Bünning, E., The Physiological Clock, 1964. Berlin.

Cold Spring Harbor Symposia on Quantitative Biology, 25 : Biological Clocks, 1960. New York. "Richter, C. P., Biological Clocks in Medicine and Psychiatry, 1965.

- Reimann, H. A., Periodic Diseases, 1963. Philadelphia.

Imrie, M. J., Mills, J. N., and Williamson, K. S., Hormones and the Kidney, Mem. Soc. Endocrinol., No. 13, 1963.

"Hunter, R., and Jones, M., Lancet, 1966, 2, 1023.

Hampp, H., Arch. Psychiat. Nervenkr., 1961, 201, 355.

Gibbons, J. L., and McHugh, P., f. psychiat. Res., 1962, 1, 162.
Brit. med. F., 1966, 2, 373. rather the opposite. The rhythm is there, timing is normal (but would it respond so well to a change in environmental daytime ?), but the peaks and troughs are less marked. The explanation of this might be the raised plasma cortisol often found in cases of depression. ${ }^{8}$ Or it could, as the authors point out, be a reflection of something in the physical pathology of the disorder. This will become clearer when diurnal excretory rhythms have been studied in other psychiatric and neurological diseases and we have a background against which to view the present results. ${ }^{9}$

\section{Abortion Law}

The Bill to " amend and clarify the law relating to termination of pregnancy by registered medical practitioners" is due to reach its Committee stage in the House of Commons on 18 January. It is a private Bill and was introduced by $\mathrm{Mr}$. David Steel, Liberal member for Roxburgh, on 15 June and received its second reading on 22 July, when it got the backing of the House by 223 votes to 29. ${ }^{1}$ Though medical men and women hold diverse views on the many controversial questions surrounding the termination of pregnancy, few of them would go all the way with the Bill as it stands, and partly to meet some of the criticisms made of it Mr. Steel, together with Dr. M. Winstanley and Dr. M. S. Miller, tabled an amendment on 21 December. The texts of the Bill and amendment are reproduced at page 1650 .

The Bill as now amended would legalize abortion if two registered medical practitioners are of the opinion, formed in good faith-

"(a) (i) that the continuance of the pregnancy would involve risk to the life or of injury to the health or wellbeing, whether physical or mental, of the pregnant woman whether before at or after the birth of the child; (ii) in determining whether or not there is risk of injury to health or wellbeing account may be taken of the patient's total environment actual or reasonably foreseeable ; or,

" $(b)$ that there is a substantial risk that if the child were born it would suffer from such physical or mental abnormalities as to be seriously handicapped; or

" (c) that the pregnant woman's capacity as a mother will be severely overstrained by the care of a child or of another child as the case may be ; or

" $(d)$ that the pregnant woman is a defective or became pregnant while under the age of sixteen or became pregnant as a result of rape."

Thus the Bill seeks to codify in statutory form the case law that has grown up on the termination of pregnancy, and at the same time to extend the grounds on which termination would be legal. The medical profession is not unanimous that the first is necessary for the patient's well being or the second desirable, but some general expressions of opinion have now been published that do show broad agreement on some of the issues to be decided. Reports have come from the council of the Royal College of Obstetricians and Gynaecologists, ${ }^{2}$ a special committee of the British Medical Association, ${ }^{3}$ the Royal Medico-Psychological Association, ${ }^{4}$ and the council of the Medical Women's Federation. ${ }^{5}$ In addition the B.M.A. and the R.C.O.G. have sent a joint statement of views to the Home Secretary, the Minister of Health, and to Mr. D. Steel and Dr. M. Winstanley, sponsors of the Bill. This was approved by the Council of the B.M.A. at its meeting last week and is published in this issue of the B.M.7. at page 1649 .

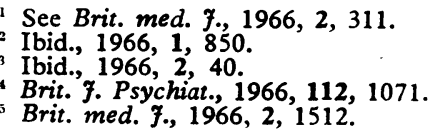


The emphasis in all these reports is on the need to keep the medical attendant's judgement free to advise the patient in her best interests. Several of them point to the danger-and this week's joint statement stresses it-of writing into an Act narrowly defined indications for termination. In fact some obstetricians of great experience believe that the translation into statute law of what they consider to be satisfactory case law can only be harmful to the patient's interests. Others, probably the majority, believe that a carefully worded Act could help, provided the indications are left in general enough terms as suggested, for instance, by the joint statement of the B.M.A. and R.C.O.G.

As a corollary to preserving the independence of the doctor's clinical judgement any Act must refrain from laying on him an obligation to reach decisions on matters outside his expert knowledge. Clause $(c)$, for example, seems to afford grounds for abortion already covered by clause $(a)$, but if it is intended to introduce new grounds it is not surprising that the joint statement of the B.M.A. and the R.C.O.G. describes it as " objectionable." For in practice medical men would face a dilemma they are not equipped to resolve if they were required to consider the pregnant woman's "capacity as a mother" separately from her "life" and " health." Again clause $(d)$ has provisions in it which, if taken separately from a consideration of the mother's health, could lead medical men into making decisions on other than their expert knowledge. Nor is clause $(b)$ free from the same defect, and it poses in addition the problem of calculating very uncertain probabilities that the baby will be seriously handicapped. It is therefore worth stressing, as the report of the Royal MedicoPsychological Association points out, that when considering the possibly deleterious effects of pregnancy psychiatrists bear in mind not only the direct but also the remote effects on the health and well-being of the mother. Though speaking for members of its specialty, the report would command agreement on that point among medical men in all branches of the profession.

The Bill contains other provisions of importance to medical men besides setting out grounds for terminating pregnancy, such as those for approval of the place where abortion may be carried out and for certification of the medical opinion that advises it. Clearly no measure dealing with so highly controversial a subject should be allowed to proceed without thørough debate. Doctors, like laymen, are far from unanimous on the points at issue, but they have a special claim to be heard if they are to be of full service to the community and especially to the sick and distracted mothers who consult them.

\section{Management of Haemophilia}

Haemophilia is a rare disease which affects only about 2,000 patients in Great Britain. Nevertheless, it is one which demands medical and social attention out of all proportion to its frequency. As Dr. J. Stuart and his colleagues point out at p. 1624 of this week's B.M.F., the recent advances in the treatment of bleeding episodes, by prolonging the life of haemophiliacs, have increased the burden of their care. Though the risk of fatal haemorrhage from serious injury is always present for the haemophiliac, the chief trials of the severely affected patient are those of recurrent loss of schooling or work as a result of repeated episodes of bleeding, and of the permanent crippling to which the latter may lead.
Efficient treatment of episodes of bleeding is no less important than the successful performance of major surgical operations in these patients, which has been made possible by the development of concentrated preparations of antihaemophilic globulin (A.H.G.) for clinical use.

Stuart and his colleagues found, in common with others, that boys under the age of 12 suffered more frequent "spontaneous" haemorrhages (mainly haemarthroses) than adolescent and adult patients, but were incapacitated for a shorter average time by each episode. Adolescents were particularly prone to haemorrhages following trauma and to haematuria, and adults to gastrointestinal haemorrhage, but at all ages haemarthroses were found to be the commonesi lesions. These authors conclude that the longer time spent in hospital in later life is partly due to chronic changes in the affected joints and surrounding muscles resulting from previous episodes, and rightly suggest that further long-term studies will be necessary to assess the value of different methods of treating acute haemarthroses. Undoubtedly, however, early replacement therapy with fresh-frozen plasma or concentrated human A.H.G.-with or without aspiration of the joint-whether or not it helps to prevent permanent damage, can greatly reduce the period of incapacity due to the acute haemarthrosis itself, and thus minimize interference with the patient's career. This is one of many reasons why hospitals undertaking the treatment of haemophilia should be able to provide a 24-hour service of skilled clinical management, backed by the laboratory control necessary for adequate replacement therapy.

Only the more severely affected patients-those with plasma factor-VIII concentrations below 1 or $2 \%$-commonly suffer from recurrent haemarthroses and other spontaneous bleeding episodes. Serious and prolonged bleeding is likely to follow trivial injury in all those with less than about $20 \%$ factor VIII, however, and even the most mildly affected haemophiliacs may bleed excessively after more serious trauma. Intracranial haemorrhage is thus a hazard in haemophilia of all degrees of severity, as Dr. S. H. Davies and his colleagues show on p. 1627 , and it does not necessarily follow recognized trauma or vascular disease. The availability of concentrated A.H.G. now makes it possible to maintain such a patient's plasma factor-VIII concentration within normal limits for days on end, and thus allows full investigation and treatment of the intracranial lesion. As Davies and his colleagues emphasize, however, such procedures should be carried out on haemophilic patients only where skilled laboratory control of treatment is available-and, it might be added, where there is a high degree of collaboration between the various members of the clinical and laboratory team.

These considerations are equally true of all major surgical operations in haemophilia, and also of dental extractions. The pioneer work of Dr. Rosemary Biggs and Professor R. G. Macfarlane and their colleagues at Oxford ${ }^{1}$ has shown that such procedures can be carried out with no more haemorrhage than would be expected in normal subjects. This is the yardstick by which all new techniques should be measured. The results of epsilon aminocaproic acid therapy for dental extraction which are reported in a preliminary communication at p. 1633 by $M$. W. Cooksey and others appear to come well up to this standard, and this ancillary method of treatment is clearly deserving of further trial Biggs, R., and Macfarlane, R. G. (eds.), Treatment of Haemophitia
and other Coagulation Disorders, 1966. Blackwell Scientific Publications, Oxford. 